\title{
Impact of glycemic control on the association of endothelial dysfunction and coronary artery disease in patients with type 2 diabetes mellitus
}

Shuai Chen ${ }^{1 \dagger}$, Ying Shen ${ }^{1 \dagger}$, Yong-Hua Liu ${ }^{2 \dagger}$, Yang Dai ${ }^{1}$, Zhi-Ming Wu ${ }^{1}$, Xiao-Qun Wang ${ }^{1}$, Chen-Die Yang ${ }^{1}$, Le-Ying Li ${ }^{1}$, Jing-Meng Liu', Li-Ping Zhang ${ }^{2}$, Wei-Feng Shen ${ }^{1}$, Ri $\mathrm{Ji}^{3^{*}}$, Lin Lu ${ }^{1 *}$ and Feng-Hua Ding ${ }^{1 *}$

\begin{abstract}
Background: We investigated whether glycemic control affects the relation between endothelial dysfunction and coronary artery disease in patients with type 2 diabetes mellitus (T2DM).

Methods: In 102 type 2 diabetic patients with stable angina, endothelial function was evaluated using brachial artery flow-mediated dilation (FMD) with high-resolution ultrasound, and significant stenosis of major epicardial coronary arteries ( $\geq 50 \%$ diameter narrowing) and degree of coronary atherosclerosis (Gensini score and SYNTAX score) were determined. The status of glycemic control was assessed by blood concentration of glycated hemoglobin (HbA1c).

Results: The prevalence of significant coronary artery stenosis (67.9\% vs. 37.0\%, $\mathrm{P}=0.002)$ and degree of coronary atherosclerosis (Gensini score: $48.99 \pm 48.88$ vs. $15.07 \pm 21.03, P<0.001$; SYNTAX score: $15.88 \pm 16.36$ vs. $7.28 \pm 10.54$, $P=0.003)$ were higher and FMD was lower $(6.03 \pm 2.08 \%$ vs. $6.94 \pm 2.20 \%, P=0.036)$ in diabetic patients with poor glycemic control (HbA1c $\geq 7.0 \% ; n=56)$ compared to those with good glycemic control (HbA1c $<7.0 \% ; n=46)$. Multivariate regression analysis revealed that tertile of FMD was an independent determinant of presence of significant coronary artery stenosis $(\mathrm{OR}=0.22795 \% \mathrm{Cl} 0.056-0.915, \mathrm{P}=0.037)$, Gensini score $(\beta=-0.470, \mathrm{P}<0.001)$ and SYNTAX score $(\beta=-0.349, P=0.004)$ in diabetic patients with poor glycemic control but not for those with good glycemic control $(P>0.05)$.
\end{abstract}

Conclusion: Poor glycemic control negatively influences the association of endothelial dysfunction and coronary artery disease in T2DM patients.

Keywords: Flow-mediated dilation, Type 2 diabetes mellitus, Coronary artery disease, Atherosclerosis

*Correspondence: jiri_1980@163.com; rjlulin1965@163.com; ruijindfh@126. com

†Shuai Chen, Ying Shen, and Yong-Hua Liu contributed equally to this study

${ }^{1}$ Department of Cardiology, Rui Jin Hospital, Shanghai Jiao Tong University School of Medicine, 197 Rui Jin Road II, Shanghai 200025, People's Republic of China

${ }^{3}$ Department of Ultrasound, Rui Jin Hospital, Shanghai Jiao Tong University School of Medicine, Shanghai, China

Full list of author information is available at the end of the article

\section{Background}

Endothelial dysfunction occurs early in the chain of atherosclerotic process and is mainly caused by systemic effects of common risk factors for coronary artery disease $[1,2]$. In current clinical practice, endothelial function is often evaluated non-invasively using flow-mediated dilation (FMD) (i.e., endothelial-dependent vasodilation) of the brachial artery with high-resolution ultrasonography $[3,4]$, which represents predominantly physiologic

(c) The Author(s) 2021. This article is licensed under a Creative Commons Attribution 4.0 International License, which permits use, sharing, adaptation, distribution and reproduction in any medium or format, as long as you give appropriate credit to the original author(s) and the source, provide a link to the Creative Commons licence, and indicate if changes were made. The images or other third party material in this article are included in the article's Creative Commons licence, unless indicated otherwise in a credit line to the material. If material is not included in the article's Creative Commons licence and your intended use is not permitted by statutory regulation or exceeds the permitted use, you will need to obtain permission directly from the copyright holder. To view a copy of this licence, visit http://creativeco mmons.org/licenses/by/4.0/. The Creative Commons Public Domain Dedication waiver (http://creativecommons.org/publicdomain/ zero/1.0/) applies to the data made available in this article, unless otherwise stated in a credit line to the data. 
or pathophysiologic response to nitric oxide-mediated endothelial activation $[5,6]$. Previous studies have frequently shown an inverse correlation between impaired brachial artery FMD and severity of coronary artery disease [7-10]. Netomo et al. [11] found that impaired endothelial function induced rapid progression of the culprit lesion, resulting in severe coronary artery stenosis as well as plaque vulnerability. More importantly, assessment of FMD provides useful information on risk stratification of patients with coronary artery disease and prediction of cardiovascular events [12-14].

Type 2 diabetes mellitus (T2DM) is independently associated with an increased risk for cardiovascular diseases that is primarily due to the early development of advanced atherosclerotic vascular changes [15]. Recently, endothelial dysfunction has received increasing attention as a potential contributor to the pathogenesis of cardiovascular diseases in type 2 diabetic patients $[12,13,16]$. The mechanisms underlying this phenomenon remain unclear but are likely to be multifactorial. The Hoorn study suggested that T2DM and endothelial dysfunction may interact with regard to the pathogenesis of cardiovascular events in a bidirectional association [13]. T2DM leads to endothelial dysfunction via, amongst others, dyslipidemia, formation of advanced glycated end products, intra-endothelial accumulation of glucose, increased oxidative stress, and low-grade inflammatory responses [17]. On the other hand, endothelial dysfunction causes or aggravates T2DM by impairing the timely access of glucose or insulin to target tissues [18].

It is well-recognized that chronic hyperglycemia could further accelerate the development of endothelial dysfunction and the pathological process of atherosclerosis, resulting in more diffuse coronary artery lesions and worse clinical outcomes $[19,20]$. Nguyen et al. [21] found that endothelial dysfunction is also independently associated with asymptomatic myocardial ischemia in patients with T2DM. However, it remains to be elucidated whether the relationship between impaired endothelial function and the severity of coronary artery disease is influenced by the status of glycemic control in type 2 diabetic patients. In this study, we investigated the association of brachial artery FMD with angiographic significant coronary artery stenosis and atherosclerosis score in a cohort of type 2 diabetic patients according to the status of glycemic control assessed by blood concentration of glycated hemoglobin (HbA1c).

\section{Methods}

This study complied with the Declaration of Helsinki. The study protocol was approved by the local hospital ethics committee, and written informed consent was obtained from all participants.

\section{Study population}

A total of 311 consecutive patients with T2DM and chest pain on exertion referred for diagnostic coronary angiography from January 2018 to May 2019 were enrolled. The diagnosis of T2DM was made according to the criteria of American Diabetes Association [22]. Hypertension and dyslipidemia were diagnosed according to seventh report of the Joint National Committee on prevention, detection, evaluation, and treatment of high blood pressure (JNC 7) and guideline of the National Cholesterol Education Program (ATP III), respectively [23, 24]. For the purpose of research, patients with acute coronary syndrome $(n=41)$, a history of coronary revascularization (coronary artery bypass grafting: $\mathrm{n}=7$; percutaneous coronary intervention: $n=25)$, chronic heart failure $(n=22)$, concomitant valvular disease $(\mathrm{n}=11)$, pulmonary heart disease $(n=11)$, congenital heart disease $(n=6)$, or cardiomyopathy $(\mathrm{n}=8)$ were excluded. We also excluded patients who had chronic kidney disease requiring hemodialysis $(n=3)$ and those who had malignant tumor or immune system disorders $(n=6)$. Patients with type 1 diabetes were excluded by measurement of C-peptide $(n=6)$ [22]. Sixty-three patients were further excluded due to unavailability of FMD. Thus, the remaining 102 patients were enrolled in the final analyses. To evaluate the influence of glycemic control on FMD and coronary artery disease, T2DM patients were arbitrarily categorized as good glycemic control $(n=46, \mathrm{HbA} 1 \mathrm{c}<7.0 \%)$ and poor glycemic control $(n=56, H b A 1 c \geq 7.0 \%)$. Baseline demographics, risk factors for coronary artery disease, and medications of all patients were recorded (Fig. 1).

\section{Coronary angiography}

Coronary angiography was performed through radial or femoral approach. Quantitative coronary angiography was performed using the Cardiovascular Measurement System version 3.0 software (Terra, GE, USA) by two interventional cardiologists who were blinded to the study protocol. Significant coronary artery disease was diagnosed if luminal diameter narrowing was estimated as $\geq 50 \%$ in a major epicardial coronary artery. Left main coronary artery stenosis $\geq 50 \%$ was considered as 2 -vessel disease. The SYNTAX score and Gensini score were calculated and used as indexes of the anatomic extension and severity of coronary atherosclerosis $[25,26]$. 


\section{Brachial artery FMD measurement}

Brachial artery FMD was assessed in the right arm using a high-resolution ultrasound machine with a $10-\mathrm{MHz}$ linear array probe and the GE Vivid 7 Imaging System following the recommended protocol [3]. Briefly, a blood pressure cuff was inflated on the forearm for $5 \mathrm{~min}$ at $200 \mathrm{mmHg}$ and the change in brachial artery diameter was measured and recorded for $3 \mathrm{~min}$ following cuff deflation. Brachial artery diameters were determined during end-diastole (gated with electrocardiogram $\mathrm{R}$ wave) by measuring the distance between the near and far wall of the intima. FMD expressed as a maximal percentage increase in brachial artery diameter from baseline was recorded. All brachial artery FMD procedures were performed by single experienced ultrasound technician, and images were measured blind to patient data and study design.

\section{Statistical analysis}

Continuous variables are presented as mean \pm standard deviation (SD) and median (25th-75th percentile) for normal and non-normal distribution, respectively, and categorical data are summarized as frequencies (percentages). We evaluated the differences in categorical variables between groups with a chi-square test. We evaluated the normality of distribution with the Kolmogorov-Smirnov test and applied logarithmic or square-root transformations to continuous variables showing a nonnormal distribution. The differences between groups for continuous variables were analyzed by Student $t$ test. We constructed multivariable logistic regression models to assess the independent determinants of coronary artery disease without (Model 1) and with (Model 2) FMD. All analyses used 2-sided tests with an overall significance level (alpha) of 0.05 , and all tests were performed with SPSS 25.0 for Windows (SPSS, Inc., Chicago, IL, USA).

\section{Results}

\section{Clinical characteristics of the population}

Patients with poor glycemic control were older $(\mathrm{P}=0.026)$ and exhibited higher serum levels of fasting blood glucose $(\mathrm{P}=0.009)$, HbA1c $(\mathrm{P}<0.001)$ and highsensitivity $\mathrm{C}$ - reactive protein (hsCRP) $(\mathrm{P}=0.002)$ compared to those with good glycemic control. However, there were no significant differences between the two groups in gender distribution, body mass index, proportion of cigarette smoking and hypertension, brachial blood pressure, kidney function and lipid profiles (all $\mathrm{P}>0.05$ ) (Table 1).

\section{Angiographic and FMD findings}

Overall, the prevalence of significant coronary artery disease was higher $(67.9 \%$ vs. $37.0 \%, \mathrm{P}=0.002)$ and the severity of coronary atherosclerosis was more prominent (Gensini score: $48.99 \pm 48.88$ vs. $15.07 \pm 21.03, \mathrm{P}<0.001$; SYNTAX score: $15.88 \pm 16.36$ vs. $7.28 \pm 10.54, \mathrm{P}=0.003$ ) in patients with poor glycemic control than those with good glycemic control. Consistently, FMD was also significantly lower in patients with poor than those with good glycemic control $(6.03 \pm 2.08 \%$ vs. $6.94 \pm 2.20 \%$, $\mathrm{P}=0.036$ ). We arbitrarily categorized FMD values of all patients into three groups according to tertile of FMD $(<5.22 \%, 5.22-7.24 \%$ and $>7.24 \%)$. In patients with poor glycemic control (HbA1c $\geq 7.0 \%$ ), a significant decrease in the prevalence of significant coronary artery disease, Gensini score and SYNTAX score was observed across the three tertiles of FMD (all P for trend $<0.05$ ), while no such trends were found in those with good glycemic control (all P for trend >0.05) (Fig. 2).

\section{Multivariate regression analysis}

Multivariate regression analyses were performed to analyze the association between coronary artery disease and FMD in two glycemic control groups. After adjustment for confounding risk factors (age, gender, hypertension, smoke, total-to-high-density lipoprotein cholesterol ratio, GFR and hsCRP), tertile of FMD (OR $=0.22795 \%$ CI $0.056-0.915, \mathrm{P}=0.037$ ) remained to be independent determinants for coronary artery disease in patients with poor glycemic control (Model 2B) (Table 2). Compared with model 1B, the addition of tertile of FMD in model $2 \mathrm{~B}$ significantly improved the goodness-of-fit and predictive performance with an increase of Nagelkerke $R^{2}$ of $8.0 \%(P=0.018)$. In multiple linear regression analysis, tertile of FMD was independently correlated with Gensini score $(\beta=-0.470, P<0.001)$ and SYNTAX score $(\beta=-0.349, P=0.004)$, respectively, in patients with poor glycemic control (Table 3 ). However, these result patterns were not found in patients with good glycemic control (Tables 2 and 3).

\section{Discussion}

The results of the present study showed that type 2 diabetic patients with poor glycemic control had lower FMD and more severe coronary artery disease than those with good glycemic control. Decreased FMD was an independent determinant of coronary artery disease and this association was more prominent in type 2 diabetic patients with poor glycemic control. These findings emphasized the importance of glycemic control in patients with T2DM.

Endothelial dysfunction is an initial manifestation in the development of atherosclerosis and also participates in plaque progression [12, 27]. It is mainly characterized by a reduction in the bioavailability of nitric oxide $(\mathrm{NO})$ and excess production of reactive oxygen species $[5,6]$. 
Table 1 Baseline characteristics of diabetic patients with good and poor glycemic control

\begin{tabular}{|c|c|c|c|}
\hline & $\begin{array}{l}\text { Good glycemic control group } \\
(n=46)\end{array}$ & $\begin{array}{l}\text { Poor glycemic control group } \\
(n=56)\end{array}$ & Pvalue \\
\hline Male, n (\%) & $33(71.7)$ & $40(71.4)$ & 0.972 \\
\hline Age, years & $61.83 \pm 9.34$ & $65.43 \pm 6.73$ & 0.026 \\
\hline Body mass index, $\mathrm{Kg} / \mathrm{m}^{2}$ & $28.41 \pm 2.59$ & $28.16 \pm 2.55$ & 0.622 \\
\hline Cigarette smoking, n (\%) & $17(37.0)$ & $22(56.4)$ & 0.810 \\
\hline Hypertension, n (\%) & $30(65.2)$ & $45(80.4)$ & 0.085 \\
\hline Systolic blood pressure, $\mathrm{mm} \mathrm{Hg}$ & $135.35 \pm 19.01$ & $141.77 \pm 18.69$ & 0.090 \\
\hline Diastolic blood pressure, mm Hg & $74.85 \pm 10.69$ & $77.82 \pm 12.42$ & 0.204 \\
\hline Fasting blood glucose, mmol/L & $6.03 \pm 0.81$ & $6.90 \pm 2.08$ & 0.009 \\
\hline $\mathrm{HbA} 1 \mathrm{c}, \%$ & $6.53 \pm 0.31$ & $8.13 \pm 1.29$ & $<0.001$ \\
\hline Serum creatinine, $\mu \mathrm{mol} / \mathrm{L}$ & $77.04 \pm 15.21$ & $78.70 \pm 17.55$ & 0.615 \\
\hline Serum uric acid, $\mu \mathrm{mol} / \mathrm{L}$ & $345.76 \pm 79.73$ & $345.98 \pm 82.74$ & 0.989 \\
\hline $\mathrm{GFR}, \mathrm{mL} / \mathrm{min} / 1.73 \mathrm{~m}^{2}$ & $86.83 \pm 14.70$ & $83.29 \pm 14.47$ & 0.225 \\
\hline Triglyceride, $\mathrm{mmol} / \mathrm{L}$ & $1.39 \pm 0.84$ & $1.92 \pm 1.75$ & 0.064 \\
\hline Total cholesterol, mmol/L & $3.84 \pm 0.88$ & $3.89 \pm 1.06$ & 0.810 \\
\hline HDL cholesterol, mmol/L & $1.23 \pm 0.28$ & $1.14 \pm 0.25$ & 0.100 \\
\hline LDL cholesterol, mmol/L & $2.25 \pm 0.80$ & $2.21 \pm 0.74$ & 0.804 \\
\hline Apolipoprotein A, g/L & $1.24 \pm 0.16$ & $1.17 \pm 0.19$ & 0.076 \\
\hline Apolipoprotein B, g/L & $0.75 \pm 0.33$ & $0.75 \pm 0.20$ & 0.975 \\
\hline Lipoprotein (a), g/L & $0.25 \pm 0.27$ & $0.33 \pm 0.35$ & 0.220 \\
\hline hsCRP, mg/L & $1.18(0.47-3.04)$ & $2.16(1.19 \sim 5.76)$ & 0.002 \\
\hline Presence of CAD, n (\%) & $17(37.0)$ & $38(67.9)$ & 0.002 \\
\hline SYNTAX score & $7.28 \pm 10.54$ & $15.88 \pm 16.36$ & 0.003 \\
\hline Gensini score & $15.07 \pm 21.03$ & $48.99 \pm 48.88$ & $<0.001$ \\
\hline \multicolumn{4}{|l|}{ Medication, n (\%) } \\
\hline ACE inhibitors/ARBs & $25(54.3)$ & $27(48.2)$ & 0.538 \\
\hline$\beta$-blockers & $28(60.9)$ & $40(71.4)$ & 0.260 \\
\hline Calcium channel blockers & $13(28.3)$ & $14(25.0)$ & 0.710 \\
\hline Statins & $43(93.5)$ & $49(87.5)$ & 0.312 \\
\hline Flow mediated dilation, $\%$ & $6.94 \pm 2.20$ & $6.03 \pm 2.08$ & 0.036 \\
\hline
\end{tabular}

Values are given as mean \pm standard deviation (SD), median (25th-75th percentile) or number (percentage)

$A C E$ angiotensin converting enzyme, $A R B$ angiotensin receptor blocker, $B U N$ blood urea nitrogen, $C A D$ coronary artery disease, GFR glomerular filtration rate, $H b A 1 C$ glycated hemoglobin, $H D L$ high-density lipoprotein, $h s C R P$ high-sensitivity C-reactive protein, $L D L$ low-density lipoprotein

Many cardiovascular risk factors contribute to endothelial dysfunction, and major elements in diabetes (such as hyperglycemia, insulin resistance, and dyslipidemia) play an important role in the pathogenesis of endothelial dysfunction, resulting in an aggravated pro-atherogenic phenotype $[12,13]$. Moreover, the diabetic milieu yields an impairment of metabolic environment homeostasis represented by chronic inflammation, oxidative stress, pro-coagulability, impaired fibrinolysis, and neovascularization abnormalities that cumulatively alter vascular structure [16, 27-29]. These pathophysiologic features, together with increased expression of pro-inflammatory cytokines, lead to abnormal endothelium-dependent vasodilation which could be investigated using FMD of the brachial artery.
The major finding of our study is that declined FMD is associated with coronary artery disease, and this association is more prominent in T2DM patients with poor glycemic control. Lower FMD is also an independent determinant of coronary artery disease in diabetic patients with poor glycemic control. These results support the notion that poor glycemic control is closely related to severe endothelial dysfunction, which aggravates the process and outcome of atherosclerosis [30]. Our results are consistent with previous studies regarding the relation of T2DM with endothelial dysfunction detected by FMD [12], and further substantiate the importance of pro-inflammatory cytokines and metabolic disturbance in the development of diabetic microand macro-vascular complications [31, 32], detrimental 


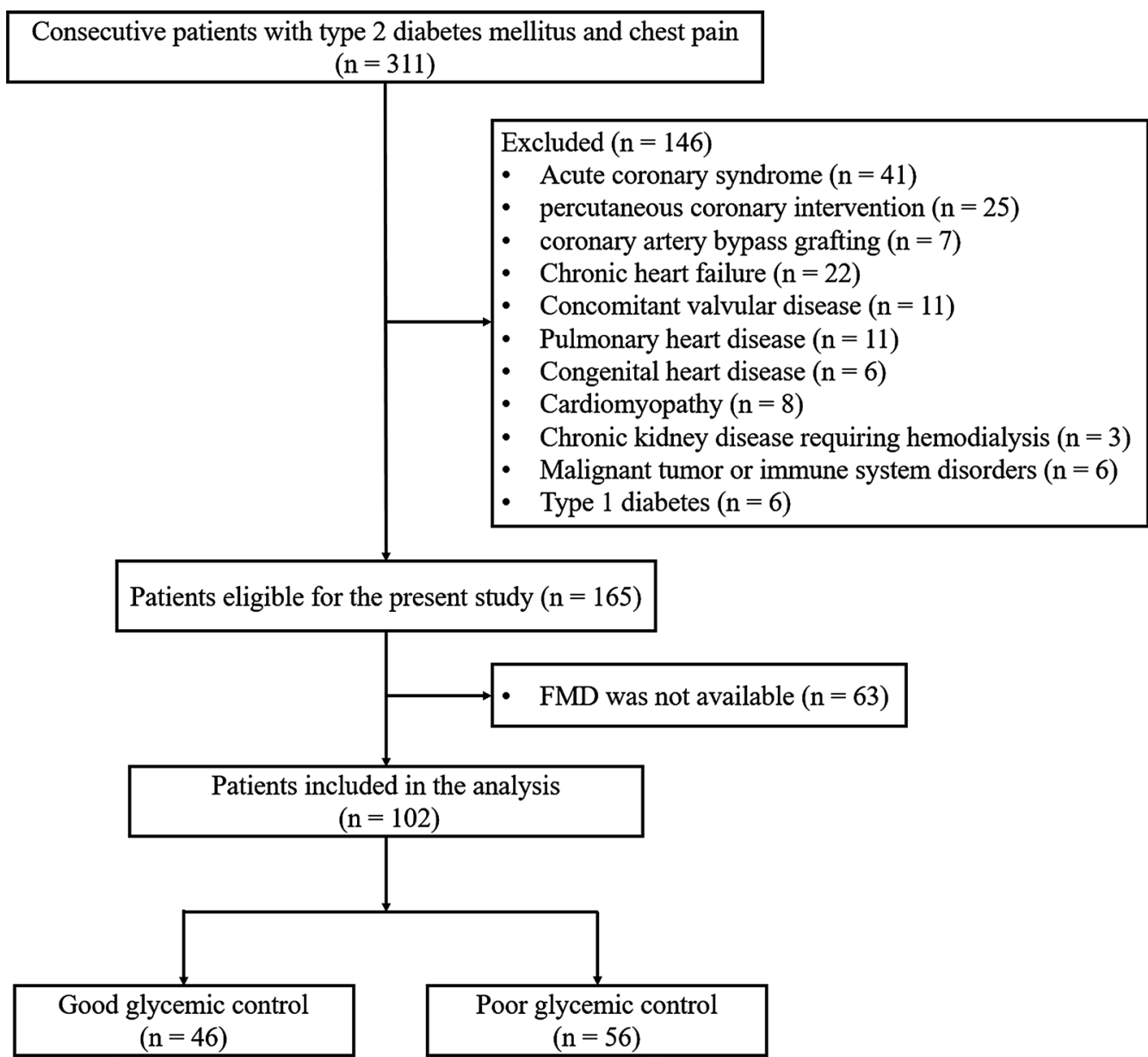

Fig. 1 Flowchart of patient enrollment. FMD, flow-mediated dilation

left ventricular remodeling as well as adverse cardiovascular outcome [33, 34]. These findings also highlight that endothelial dysfunction may be a critical early target for preventing atherosclerosis in patients with T2DM as abnormalities in vascular reactivity and biochemical markers of endothelial cell activation are present early in individuals at risk of developing T2DM, and repair of plaque rupture and reendothelialization of coronary lesions are often asymptomatic or silent in most cases [35].

In this perspective, our observations have important clinical relevance. Previous studies have shown that treatment with angiotensin-converting enzyme inhibitors or angiotensin-receptor blockers is associated with improvement of endothelial function and reduced incidence of new-onset diabetes possible through increased serum bradykinin levels which improves insulin-mediated glucose uptake and endothelial function, increased vascular NO activity, and reduced vascular inflammation $[12,36]$. Lipid-lowering agents particularly statins not only decrease serum low-density lipoprotein (LDL) cholesterol and hsCRP levels and risk of cardiovascular disease, but also substantially improve the clinical outcome of patients with coronary artery disease. In addition, several studies have demonstrated an improvement in endothelial function before the reduction in serum cholesterol levels [37, 38]. However, it should be noted that statin use may increase fasting blood glucose and HbA1c levels due to increased insulin resistance or reduce insulin release, which could contribute to the genesis of diabetes [35]. Proprotein convertase subtilisin/kexin type 9 (PCSK9) inhibitors have been shown to dramatically reduce plasma LDL cholesterol and cardiovascular risk in atherosclerotic disease patients, without increasing the risk of new-onset diabetes and worsening glycemia [39].

Despite conflicting results in the relationship of HgbA1c to cardiac outcomes and survival, efforts have been made to achieve optimal glycemic control for patients with T2DM because hyperglycemia is a major causal factor in the development of endothelial 
Table 2 Multivariate logistic regression analyses for coronary artery disease in diabetic patients with good and poor glycemic control

\begin{tabular}{|c|c|c|c|c|c|c|}
\hline \multirow[t]{2}{*}{ Variables } & & \multicolumn{2}{|c|}{ Good glycemic control group } & & \multicolumn{2}{|c|}{ Poor glycemic control group } \\
\hline & & OR $(95 \% \mathrm{Cl})$ & P value & & $\mathrm{OR}(95 \% \mathrm{Cl})$ & P value \\
\hline & Model 1A & & & Model 1B & & \\
\hline Male & & $1.492(0.137-16.197)$ & 0.742 & & $8.47(0.6-119.56)$ & 0.114 \\
\hline Age & & $0.973(0.874-1.084)$ & 0.622 & & $0.953(0.806-1.126)$ & 0.573 \\
\hline Body mass index & & $0.882(0.585-1.328)$ & 0.547 & & $1.592(0.954-2.656)$ & 0.075 \\
\hline Smoke & & $1.800(0.372-8.719)$ & 0.465 & & $3.588(0.573-22.482)$ & 0.172 \\
\hline Hypertension & & $7.320(1.167-45.933)$ & 0.034 & & $3.332(0.435-25.548)$ & 0.247 \\
\hline Total-to-HDL cholesterol ratio & & $0.983(0.503-1.923)$ & 0.960 & & 8.945 (2.004-39.919) & 0.004 \\
\hline GFR & & $0.962(0.898-1.030)$ & 0.269 & & $0.948(0.866-1.037)$ & 0.243 \\
\hline \multirow[t]{2}{*}{ Log-transferred hsCRP } & & $0.984(0.539-1.795)$ & 0.958 & & $1.415(0.701-2.857)$ & 0.333 \\
\hline & Model 2A & & & Model 2B & & \\
\hline Male & & $2.668(0.187-38.168)$ & 0.470 & & $14.289(0.707-288.728)$ & 0.083 \\
\hline Age & & $0.949(0.849-1.061)$ & 0.358 & & $0.934(0.774-1.126)$ & 0.473 \\
\hline Body mass index & & $0.970(0.622-1.513)$ & 0.894 & & $1.753(0.943-3.258)$ & 0.076 \\
\hline Smoke & & $2.408(0.458-12.679)$ & 0.300 & & $3.725(0.501-27.674)$ & 0.199 \\
\hline Hypertension & & $8.476(1.202-59.789)$ & 0.032 & & $5.577(0.470-66.239)$ & 0.173 \\
\hline Total-to-HDL cholesterol ratio & & $1.158(0.562-2.389)$ & 0.691 & & $11.882(1.713-82.402)$ & 0.012 \\
\hline GFR & & $0.964(0.899-1.034)$ & 0.303 & & $0.941(0.847-1.046)$ & 0.261 \\
\hline Log-transferred hsCRP & & $0.815(0.423-1.570)$ & 0.540 & & $1.015(0.462-2.228)$ & 0.971 \\
\hline Tertiles of FMD & & $0.410(0.128-1.307)$ & 0.132 & & $0.227(0.056-0.915)$ & 0.037 \\
\hline
\end{tabular}

Values are odds ratios (95\% confidence interval)

FMD flow-mediated dilation, GFR glomerular filtration rate, $H D L$ high-density lipoprotein, $h s C R P$ high-sensitivity C-reactive protein

Table 3 Linear regression models of Gensini score and Syntax score for diabetic patients with good and poor glycemic control

\begin{tabular}{|c|c|c|c|c|c|c|c|c|}
\hline \multirow[t]{3}{*}{ Variables } & \multicolumn{4}{|c|}{ Gensini score } & \multicolumn{4}{|c|}{ SYNTAX score } \\
\hline & \multicolumn{2}{|c|}{ Good glycemic control } & \multicolumn{2}{|c|}{ Poor glycemic control } & \multicolumn{2}{|c|}{ Good glycemic control } & \multicolumn{2}{|c|}{ Poor glycemic control } \\
\hline & Beta & Pvalue & Beta & P value & Beta & P value & Beta & Pvalue \\
\hline Male & 0.044 & 0.849 & 0.170 & 0.159 & 0.024 & 0.918 & 0.204 & 0.105 \\
\hline Age & -0.174 & 0.398 & 0.217 & 0.074 & -0.181 & 0.374 & 0.227 & 0.073 \\
\hline Body mass index & 0.022 & 0.926 & 0.076 & 0.522 & -0.017 & 0.940 & 0.096 & 0.436 \\
\hline Smoke & 0.088 & 0.591 & 0.237 & 0.039 & 0.124 & 0.445 & 0.270 & 0.024 \\
\hline Hypertension & 0.440 & 0.006 & 0.093 & 0.369 & 0.431 & 0.007 & 0.069 & 0.521 \\
\hline Total-to-HDL cholesterol ratio & 0.114 & 0.458 & 0.326 & 0.004 & -0.047 & 0.756 & 0.394 & 0.001 \\
\hline GFR & -0.227 & 0.264 & 0.101 & 0.405 & -0.262 & 0.193 & -0.052 & 0.678 \\
\hline Log-transferred hsCRP & 0.297 & 0.100 & 0.185 & 0.100 & 0.280 & 0.115 & 0.081 & 0.481 \\
\hline Tertiles of FMD & -0.088 & 0.595 & -0.470 & $<0.001$ & -0.126 & 0.444 & -0.349 & 0.004 \\
\hline
\end{tabular}

FMD flow-mediated dilation, GFR glomerular filtration rate, $H D L$ high-density lipoprotein, $h s C R P$ high-sensitivity $C$-reactive protein

dysfunction and chronic diabetic vascular complications through multiple mechanisms [12, 40]. Sara and co-workers reported that microvascular dysfunction is associated with poor glycemic control amongst female diabetics with non-obstructive coronary artery disease, which results in reduced myocardial flow reserve and microvascular angina [41]. Oral hypoglycemic agents have been shown to play a role in improving endothelial function beyond their glycemic control [40, 42, 43]. FMD was improved after 3 months of treatment with metformin [42]. In a single-arm study, sitagliptin, a dipeptidyl peptidase-4 inhibitor, showed an improvement in FMD measurements in moderately controlled patients with T2DM, in addition to a decrease in HbA1c within 2 weeks of therapy [44]. Sodium-glucose cotransporter 2 (SGLT2) inhibitors are a relatively new class of 

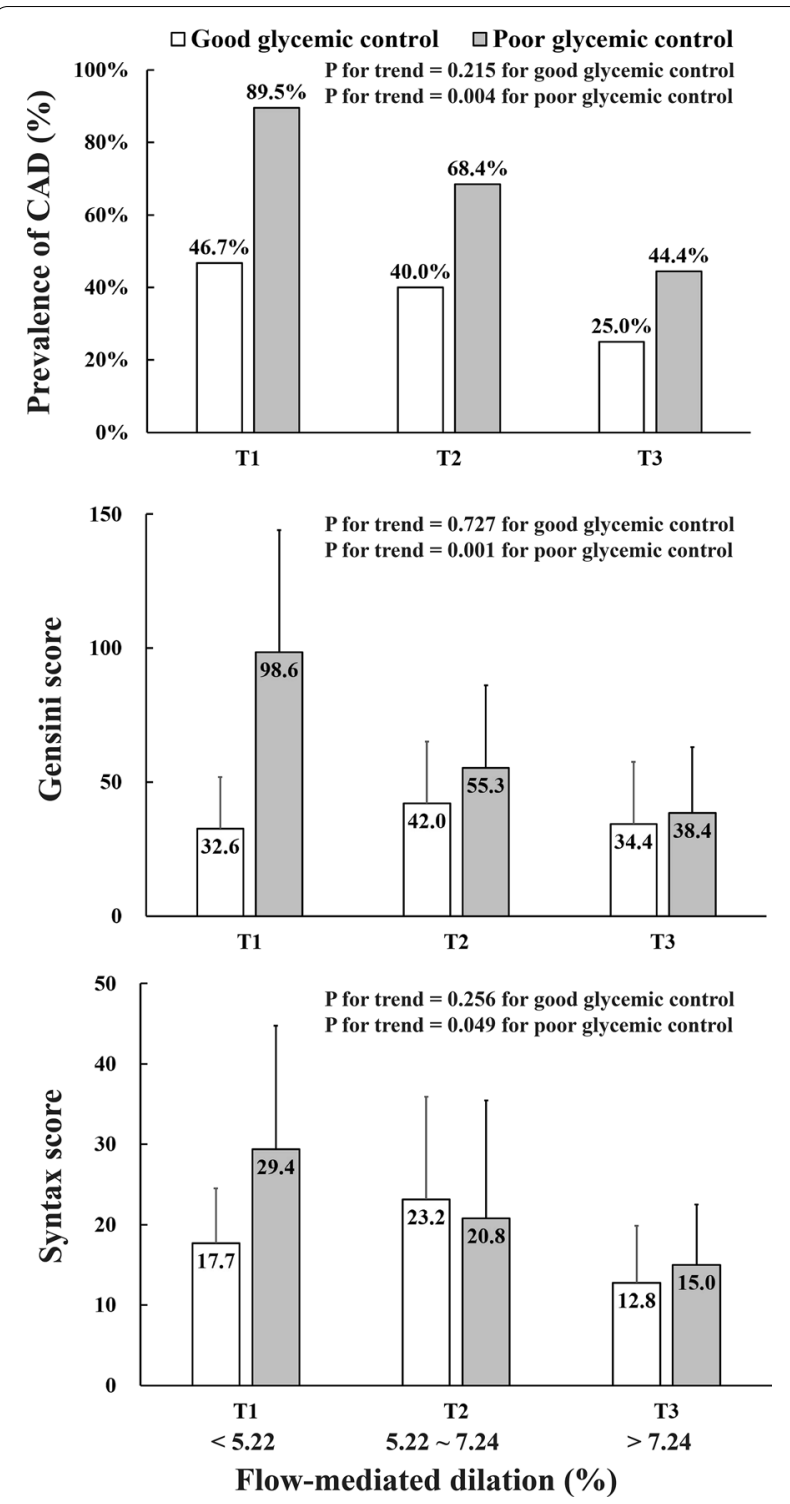

Fig. 2 Significant decrease in the prevalence and severity of coronary artery disease (CAD) across tertiles of brachial artery flow-mediated dilation (FMD) in type 2 diabetic patients with good or poor glycemic control

oral anti-diabetic agents with promising cardiovascular benefits, including a slight reduction in blood pressure and arterial stiffness [45-47]. The DEFENSE study demonstrated that with dapagliflozin add-on therapy to metformin for 16 weeks, vascular endothelial function as assessed by FMD was significantly ameliorated in patients with inadequately controlled early stage T2DM, and such a beneficial effect was due to improved oxidative stress [48]. In the EDIFIED trial, a 12-week therapy with dapagliflozin, in addition to insulin and metformin therapies, resulted in significant reductions in $\mathrm{HbA} 1 \mathrm{c}$, fasting blood glucose, and surrogate markers of endothelial function. Furthermore, there was a significant association between reduction in $\mathrm{HbAlc}$ and improvement in FMD in the dapagliflozin group [49]. These observations together with our present findings should have an impetus on further investigations regarding the protective role of new anti-diabetic agents especially SGLT2 on endothelial function and their ability to suppress the progression of coronary atherosclerosis.

\section{Limitation}

We recognize that there are certain limitations in this study. First, the study is cross-sectional for the point of FMD and coronary artery disease investigation, thereby allowing us to detect association, not to establish a causative link of FMD with coronary atherosclerosis and to predict clinical outcome. Nevertheless, prescription data were accurately captured by using standard database software, thus these results reflect true associations in the real-world setting. Second, only single measurement of baseline HbA1c level was used, which may not accurately reflect the exact status of glycemic control during follow-up. Recent studies have shown an advantage of measuring visit-to-visit HbA1c variability (i.e., long-term glycemic variability) in the assessment of risk of cardiovascular disease for patients with T2DM [50-52]. Likewise, the duration of T2DM was not determined, but impairment of endothelium-dependent vasodilation is independently associated with long-term diabetic duration [53]. Finally, it is possible that the prevalence and course of coronary artery disease could also be influenced by the medical treatments and other risk factors.

\section{Conclusion}

This study indicates that poor glycemic control exerts an adverse effect on endothelial function, and aggravates coronary atherosclerosis in T2DM. These observations, at least partly, provide substantial insight into the management of type 2 diabetic patients with coronary artery disease.

\section{Abbreviations}

FMD: Flow-mediated dilation; GFR: Glomerular filtration rate; HbA1c: Glycated hemoglobin A1 c; HDL: High-density lipoprotein; SGLT2: Sodium-glucose cotransporter 2; T2DM: Type 2 diabetes mellitus.

\section{Acknowledgements}

None.

\section{Authors' contributions}

SC, YHL, YD, XQW and FHD participated in study design, data analysis and interpretation, and drafting manuscript. YS, ZMW, CDY, LYL, JML, LPZ, RJ performed data collection. FHD, LL and WFS revised the manuscript before final approval. All authors read and approved the final manuscript. 


\section{Funding}

This study was supported by the National Natural Science Foundation of China (81770437, 81770447, 81870179, 81870357, 81970362, 81970293, 8200369), Medico-engineering Research Project of Shanghai Jiao Tong University (YG2021ZD04), Shanghai Municipal Commission of Health and Family Planning (2018YQ17, 20194Y0042), and Shanghai Municipal Education Commission-Gaofeng Clinical Medicine Grant Support (20181801).

\section{Availability of data and materials}

The datasets used and/or analyzed during the current study are available from the corresponding author on reasonable request.

\section{Declarations}

\section{Ethics approval and consent to participate}

The study was approved by the Hospital Ethics Committee, and written informed consent was obtained from all patients.

\section{Consent for publication}

Not applicable.

\section{Competing interests}

The authors declare that they have no competing interests.

\section{Author details}

${ }^{1}$ Department of Cardiology, Rui Jin Hospital, Shanghai Jiao Tong University School of Medicine, 197 Rui Jin Road II, Shanghai 200025, People's Republic of China. ${ }^{2}$ Department of Cardiology, Bao Shan People's Hospital, Baoshan, Yunnan Province, China. ${ }^{3}$ Department of Ultrasound, Rui Jin Hospital, Shanghai Jiao Tong University School of Medicine, Shanghai, China.

Received: 19 January 2021 Accepted: 5 March 2021

Published online: 13 March 2021

\section{References}

1. Gutierrez E, Flammer AJ, Lerman LO, Elizaga J, Lerman A, Fernandez-Aviles F. Endothelial dysfunction over the course of coronary artery disease. Eur Heart J. 2013;34(41):3175-81.

2. Matsuzawa Y, Lerman A. Endothelial dysfunction and coronary artery disease: assessment, prognosis, and treatment. Coron Artery Dis. 2014;25(8):713-24.

3. Korkmaz H, Onalan O. Evaluation of endothelial dysfunction: flow-mediated dilation. Endothelium. 2008;15(4):157-63.

4. Thijssen DHJ, Bruno RM, van Mil A, Holder SM, Faita F, Greyling A, Zock PL, Taddei S, Deanfield JE, Luscher T, et al. Expert consensus and evidencebased recommendations for the assessment of flow-mediated dilation in humans. Eur Heart J. 2019;40(30):2534-47.

5. Quyyumi AA, Dakak N, Andrews NP, Husain S, Arora S, Gilligan DM, Panza JA, Cannon RO. Nitric oxide activity in the human coronary circulation. Impact of risk factors for coronary atherosclerosis. J Clin Invest. 1995:95(4):1747-55

6. Ren X, Ren L, Wei Q, Shao H, Chen L, Liu N. Advanced glycation end-products decreases expression of endothelial nitric oxide synthase through oxidative stress in human coronary artery endothelial cells. Cardiovasc Diabetol. 2017:16(1):52.

7. Kaku B, Mizuno S, Ohsato K, Murakami T, Moriuchi I, Arai Y, Nio Y, Hirase H, Nagata M, Takahashi Y, et al. The correlation between coronary stenosis index and flow-mediated dilation of the brachial artery. Jpn Circ J. 1998;62(6):425-30.

8. Irace C, De Rosa S, Tripolino C, Ambrosio G, Covello C, Abramo E, Carallo C, Mongiardo A, Spaccarotella C, Torella D, et al. Delayed flow-mediated vasodilation and critical coronary stenosis. J Investig Med. 2018;66(5):1-7.

9. Simova I, Katova T, Denchev S. Diagnostic accuracy of flow-mediated dilatation and intima-media thickness for the presence of significant coronary artery disease. J Am Soc Hypertens. 2009;3(6):388-94.

10. Arakawa K, Ohno M, Horii M, Ishigami T, Kimura K, Tamura K. Impact of flow-mediated dilatation and coronary calcification in providing complementary information on the severity of coronary artery disease. Atherosclerosis. 2017;267:146-52.

11. Nemoto T, Minami Y, Yamaoka-Tojo M, Sato T, Muramatsu Y, Kakizaki R, Fujiyoshi K, Hashimoto T, Meguro K, Shimohama T, et al. Impaired flow-mediated dilation and severity and vulnerability of culprit plaque in patients with coronary artery disease. Int Heart J. 2019;60(3):539-45.

12. Hadi HA, Suwaidi JA. Endothelial dysfunction in diabetes mellitus. VasC Health Risk Manag. 2007;3(6):853-76.

13. van Sloten TT, Henry RM, Dekker JM, Nijpels G, Unger T, Schram MT, Stehouwer CD. Endothelial dysfunction plays a key role in increasing cardiovascular risk in type 2 diabetes: the Hoorn study. Hypertension. 2014;64(6):1299-305.

14. Bruno RM, Penno G, Daniele G, Pucci L, Lucchesi D, Stea F, Landini L, Cartoni G, Taddei S, Ghiadoni L, et al. Type 2 diabetes mellitus worsens arterial stiffness in hypertensive patients through endothelial dysfunction. Diabetologia. 2012;55(6):1847-55.

15. Paneni F, Beckman JA, Creager MA, Cosentino F. Diabetes and vascular disease: pathophysiology, clinical consequences, and medical therapy: part I. Eur Heart J. 2013;34(31):2436-43.

16. Xu J, Zou MH. Molecular insights and therapeutic targets for diabetic endothelial dysfunction. Circulation. 2009;120(13):1266-86.

17. Domingueti CP, Dusse LM, Carvalho M, de Sousa LP, Gomes KB, Fernandes AP. Diabetes mellitus: The linkage between oxidative stress, inflammation, hypercoagulability and vascular complications. J Diabetes Compl. 2016;30(4):738-45

18. Muris DM, Houben AJ, Schram MT, Stehouwer CD. Microvascular dysfunction is associated with a higher incidence of type 2 diabetes mellitus: a systematic review and meta-analysis. Arterioscler Thromb Vasc Biol. 2012;32(12):3082-94.

19. Sharma PK, Agarwal S, Ellis SG, Goel SS, Cho L, Tuzcu EM, Lincoff AM, Kapadia SR. Association of glycemic control with mortality in patients with diabetes mellitus undergoing percutaneous coronary intervention. Circ Cardiovasc Interv. 2014;7(4):503-9.

20. Kassaian SE, Goodarzynejad H, Boroumand MA, Salarifar M, Masoudkabir F, Mohajeri-Tehrani MR, Pourhoseini H, Sadeghian S, Ramezanpour N, Alidoosti $\mathrm{M}$, et al. Glycosylated hemoglobin ( $\mathrm{HbA} 1 \mathrm{c})$ levels and clinical outcomes in diabetic patients following coronary artery stenting. Cardiovasc Diabetol. 2012;11:82.

21. Nguyen MT, Pham I, Valensi P, Rousseau H, Vicaut E, Laguillier-Morizot C, Nitenberg A, Cosson E. Flow-mediated-paradoxical vasoconstriction is independently associated with asymptomatic myocardial ischemia and coronary artery disease in type 2 diabetic patients. Cardiovasc Diabetol. 2014;13:20

22. American Diabetes A. Standards of medical care in diabetes-2012. Diabetes Care. 2012;35(Suppl 1):S11-63.

23. Chobanian AV, Bakris GL, Black HR, Cushman WC, Green LA, Izzo JL Jr, Jones DW, Materson BJ, Oparil S, Wright JT Jr, et al. Seventh report of the Joint National Committee on Prevention, Detection, Evaluation, and Treatment of High Blood Pressure. Hypertension. 2003;42(6):1206-52.

24. Expert Panel on Detection E, Treatment of High Blood Cholesterol in A. Executive Summary of The Third Report of The National Cholesterol Education Program (NCEP) Expert Panel on Detection, Evaluation, And Treatment of High Blood Cholesterol In Adults (Adult Treatment Panel III). JAMA. 2001;285(19):2486-97.

25. Lu L, Pu LJ, Zhang Q, Wang LJ, Kang S, Zhang RY, Chen QJ, Wang JG, De Caterina R, Shen WF. Increased glycated albumin and decreased esRAGE levels are related to angiographic severity and extent of coronary artery disease in patients with type 2 diabetes. Atherosclerosis. 2009;206(2):540-5.

26. Lu L, Wang YN, Li MC, Wang HB, Pu LJ, Niu WQ, Meng H, Yang EL, Zhang RY, Zhang $Q$, et al. Reduced serum levels of vasostatin-2, an antiinflammatory peptide derived from chromogranin A, are associated with the presence and severity of coronary artery disease. Eur Heart J. 2012:33(18):2297-306.

27. Eelen G, de Zeeuw P, Simons M, Carmeliet P. Endothelial cell metabolism in normal and diseased vasculature. Circ Res. 2015;116(7):1231-44.

28. Tuttolomondo A, Maida C, Pinto A. Diabetic foot syndrome: Immuneinflammatory features as possible cardiovascular markers in diabetes. World J Orthop. 2015;6(1):62-76.

29. Di Raimondo D, Tuttolomondo A, Buttà C, Casuccio A, Giarrusso L, Miceli G, Licata G, Pinto A. Metabolic and anti-inflammatory effects of 
a home-based programme of aerobic physical exercise. Int J Clin Pract. 2013;67(12):1247-53.

30. Simova II, Denchev SV, Dimitrov SI, Ivanova R. Endothelial function in patients with and without diabetes mellitus with different degrees of coronary artery stenosis. J Clin Ultrasound. 2009;37(1):35-9.

31. Tuttolomondo A, Maida C, Pinto A. Diabetic foot syndrome as a possible cardiovascular marker in diabetic patients. J Diabetes Res. 2015;2015:268390.

32. Pinto A, Tuttolomondo A, Di Raimondo D, Fernandez P, Licata G. Risk factors profile and clinical outcome of ischemic stroke patients admitted in a Department of Internal Medicine and classified by TOAST classification. Int Angiol. 2006;25(3):261-7.

33. Bissinger A, Grycewicz T, Grabowicz W, Lubiński A. Endothelial function and left ventricular remodeling in diabetic and non-diabetic patients after acute coronary syndrome. Med Sci Monit. 2011;17(2):CR73-7.

34. Villano A, Mencarelli E, Melita V, Rizzi A, Lamendola P, De Vita A, Manfredonia L, Ravenna SE, Pitocco D, Lanza GA, Crea F. Endothelial dysfunction and cardiovascularoutcome in asymptomatic patients with type 2 diabetes: A pilot study. Diabetes Metab Res Rev. 2020;36(1):e3215.

35. Esper RJ, Nordaby RA. Cardiovascular events, diabetes and guidelines: the virtue of simplicity. Cardiovasc Diabetol. 2019;18(1):42.

36. Chiesa ST, Marcovecchio ML, Benitez-Aguirre P, Cameron FJ, Craig ME, Couper JJ, Davis EA, Dalton RN, Daneman D, Donaghue KC, et al. Vascular effects of ACE (angiotensin-converting enzyme) inhibitors and statins in adolescents with type 1 diabetes. Hypertension. 2020;76(6):1734-43.

37. Katsiki N, Reiner Z, Tedeschi Reiner E, Al-Rasadi K, Pirro M, Mikhailidis DP, Sahebkar A. Improvement of endothelial function by pitavastatin: a metaanalysis. Expert Opin Pharmacother. 2018;19(3):279-86.

38. Shinnakasu A, Yamamoto K, Kurano M, Arimura H, Arimura A, Kikuti A, Hashiguchi H, Deguchi T, Nishio Y. The combination therapy of fenofibrate and ezetimibe improved lipid profile and vascular function compared with statins in patients with type 2 diabetes. J Atheroscler Thromb. 2017;24(7):735-48.

39. Sabatine MS, Leiter LA, Wiviott SD, Giugliano RP, Deedwania P, De Ferrari GM, Murphy SA, Kuder JF, Gouni-Berthold I, Lewis BS, et al. Cardiovascular safety and efficacy of the PCSK9 inhibitor evolocumab in patients with and without diabetes and the effect of evolocumab on glycaemia and risk of new-onset diabetes: a prespecified analysis of the FOURIER randomised controlled trial. Lancet Diabetes Endocrinol. 2017;5(12):941-50.

40. Huang R, Abdelmoneim SS, Nhola LF, Basu R, Basu A, Mulvagh SL. Relationship between glycosylated hemoglobin A1c and coronary flow reserve in patients with Type 2 diabetes mellitus. Expert Rev Cardiovasc Ther. 2015;13(4):445-53.

41. Sara JD, Taher R, Kolluri N, Vella A, Lerman LO, Lerman A. Coronary microvascular dysfunction is associated with poor glycemic control amongst female diabetics with chest pain and non-obstructive coronary artery disease. Cardiovasc Diabetol. 2019;18(1):22.

42. Vitale C, Mercuro G, Cornoldi A, Fini M, Volterrani M, Rosano GM. Metformin improves endothelial function in patients with metabolic syndrome. J Intern Med. 2005;258(3):250-6.
43. Kubota Y, Miyamoto M, Takagi G, Ikeda T, Kirinoki-lchikawa S, Tanaka K, Mizuno K. The dipeptidyl peptidase-4 inhibitor sitagliptin improves vascular endothelial function in type 2 diabetes. J Korean Med Sci. 2012;27(11):1364-70.

44. Batzias K, Antonopoulos AS, Oikonomou E, Siasos G, Bletsa E, Stampouloglou PK, Mistakidi CV, Noutsou M, Katsiki N, Karopoulos P, et al. Effects of newer antidiabetic drugs on endothelial function and arterial stiffness: a systematic review and meta-analysis. J Diabetes Res. 2018;2018:1232583.

45. Inzucchi SE, Zinman B, Wanner C, Ferrari R, Fitchett D, Hantel S, Espadero RM, Woerle HJ, Broedl UC, Johansen OE. SGLT-2 inhibitors and cardiovascular risk: proposed pathways and review of ongoing outcome trials. Diab Vasc Dis Res. 2015;12(2):90-100.

46. Zinman B, Wanner C, Lachin JM, Fitchett D, Bluhmki E, Hantel S, Mattheus M, Devins T, Johansen OE, Woerle HJ, et al. Empagliflozin, cardiovascular outcomes, and mortality in type 2 diabetes. N Engl J Med. 2015;373(22):2117-28.

47. Shen Y, Dai Y, Wang XQ, Zhang RY, Lu L, Ding FH, Shen WF. Searching for optimal blood pressure targets in type 2 diabetic patients with coronary artery disease. Cardiovasc Diabetol. 2019;18(1):160.

48. Shigiyama F, Kumashiro N, Miyagi M, Ikehara K, Kanda E, Uchino H, Hirose T. Effectiveness of dapagliflozin on vascular endothelial function and glycemic control in patients with early-stage type 2 diabetes mellitus: DEFENCE study. Cardiovasc Diabetol. 2017;16(1):84.

49. Zainordin NA, Hatta S, Mohamed Shah FZ, Rahman TA, Ismail N, Ismail Z, Abdul Ghani R. Effects of dapagliflozin on endothelial dysfunction in type 2 diabetes with established ischemic heart disease (EDIFIED). J Endocr Soc. 2020;4(1):bvz017.

50. Slieker RC, van der Heijden A, Nijpels G, Elders PJM, t Hart LM, Beulens JWJ. Visit-to-visit variability of glycemia and vascular complications: the Hoorn Diabetes Care System cohort. Cardiovasc Diabetol. 2019;18(1):170.

51. Yang CD, Shen Y, Lu L, Yang ZK, Hu J, Zhang RY, Shen WF, Ding FH, Wang XQ. Visit-to-visit $\mathrm{HbA1}$ c variability is associated with in-stent restenosis in patients with type 2 diabetes after percutaneous coronary intervention. Cardiovasc Diabetol. 2020;19(1):133.

52. Shen Y, Zhou J, Shi L, Nauman E, Katzmarzyk PT, Price-Haywood EG, Horswell R, Bazzano AN, Nigam S, Hu G. Association between visit-to-visit $\mathrm{HbA1C}$ variability and the risk of cardiovascular disease in patients with type 2 diabetes. Diabetes Obes Metab. 2021;23(1):125-35.

53. Naka KK, Papathanassiou K, Bechlioulis A, Kazakos N, Pappas K, Tigas S, Makriyiannis D, Tsatsoulis A, Michalis LK. Determinants of vascular function in patients with type 2 diabetes. Cardiovasc Diabetol. 2012;11:127.

\section{Publisher's Note}

Springer Nature remains neutral with regard to jurisdictional claims in published maps and institutional affiliations.

\footnotetext{
Ready to submit your research? Choose BMC and benefit from:

- fast, convenient online submission

- thorough peer review by experienced researchers in your field

- rapid publication on acceptance

- support for research data, including large and complex data types

- gold Open Access which fosters wider collaboration and increased citations

- maximum visibility for your research: over $100 \mathrm{M}$ website views per year
}

At $\mathrm{BMC}$, research is always in progress.

Learn more biomedcentral.com/submissions 